\title{
Improving electrochemical corrosion properties of ZE41A magnesium alloy via hydrothermal treatment
}

\author{
Yuguang Zhang ${ }^{1}$, Fan Zhang ${ }^{1 *}$, Qingpeng Cheng ${ }^{2}$, Xiuling Huang ${ }^{2}$, Kai Zhang ${ }^{1}$, Guosen Wen ${ }^{1}$ and Chaoxiong Zhang ${ }^{1}$ \\ ${ }^{1}$ School of Materials Engineering, Shanghai University of Engineering Science, Shanghai 201620, China \\ ${ }^{2}$ College of Mechanical and Electronic Engineering, Nanjing Forestry University, Nanjing 210037, China
}

\begin{abstract}
ZE41A magnesium alloy was selected as matrix material, using hydrothermal method for the synthesis of the surface coating. The formation of anti-corrosion coatings on the surface of magnesium alloy was investigated in pure water. By adjusting the experimental parameters such as the hydrothermal time (1-3 h) and the hydrothermal temperature $\left(120-160{ }^{\circ} \mathrm{C}\right)$, the generation of the coating on the magnesium alloy surface is regulated. The surface morphologies, composition phase, and corrosion resistance of the hydrothermal conversion coatings were investigated by the method of scanning electron microscopy (SEM), energy dispersive spectroscopy (EDS), X-ray diffraction (XRD) and electrochemical corrosion tests. Results show that prolonged hydrothermal time and increased hydrothermal temperature change the morphologies as well as the chemical compositions of formed coatings from a relative loose structure with few magnesium hydroxides into a fine dense one with higher amount of magnesium hydroxide.
\end{abstract}

\section{Introduction}

Mg alloys are of industrial interest as structural metals due to their low density and high strength to weight ratio[1,2]. However, their poor corrosion resistance limits their applications $[3,4]$. To improve the corrosion resistance of magnesium alloys, some techniques including alloying [5], laser surface modification[6] and electrochemical deposition method[7] have been studied. Among them, the hydrothermal (HT) method [8] is quite attractive due to the simple one-step process, environmental friendliness, and easy design of the reaction conditions. The corrosion properties of magnesium alloys can be enhanced by the formation of oxide and/or hydroxide films via HT treatment [9]. $\mathrm{MgO}$ and $\mathrm{Mg}(\mathrm{OH})_{2}$ constitute good protective films on account of the nontoxic and biocompatible properties[10].

In this work, ZE41A magnesium alloy samples are treated by the HT method at different temperatures and for various time durations to form corrosion resistant films. The films are characterized by scanning electron microscopy (SEM), energy-dispersive X-ray spectroscopy (EDS), and X-ray diffraction (XRD) and the corrosion behavior is evaluated by electrochemical tests including open-circuit potential, electrochemical impedance spectrum and potentiodynamic polarization.

\section{Experimental}

The ZE41A magnesium alloy specimens with the size of $10 \mathrm{~mm} \times 10 \mathrm{~mm} \times 5 \mathrm{~mm}$ were cut from a cast ingot. The hydrothermal synthesis processing was executed in stainless steel autoclave with a Teflon container (100 mL). The de-ionized water was poured into the Teflon container to $70 \%$ volume as the reaction solution. The reactor was heated via an electric furnace at various temperatures $\left(120-160^{\circ} \mathrm{C}\right)$ for $1-3 \mathrm{~h}$. The hydrothermal-synthesizing time was counted after the furnace temperature reached the set temperature. Before synthesizing processing, all the specimens were polished with $\mathrm{SiC}$ papers up to 2000 grades, ultrasonically cleaned in acetone and ethanol for 5 min each, and dried in air.

The surface micro-morphologies of the coatings were examined by scanning electron microscope (SEM, S3400 N, Hitachi, Japan). Prior to the observation, all the samples were coated by platinum. The element distribution of the cast and HT-treated alloy were characterized by the energy dispersive X-ray spectrometer (EDS). X-ray diffraction (XRD) analysis of the coated sample was performed using a Bruker D8 Advance diffractometer (Bruker AXS, Karlsruhe, Germany) with $\mathrm{Cu} \mathrm{K} \alpha 1$ radiation. The $\theta-2 \theta$ diffraction patterns were scanned from $10^{\circ}$ to $90^{\circ}$ with a scanning rate of $4^{\circ}$ per minute.

Hank's solution was selected as the corrosion media and its chemical composition can be found elsewhere[11,12]. The electrochemical tests were conducted via a Parstat 4000 (Princeton, Oak Ridge, TN, USA) advanced potentiostat with a three-electrode cell. Before the electrochemical test, the coated samples and the substrate samples were moulded in epoxy with a squared exposure of $1 \mathrm{~cm}^{2}$. All exposed surfaces were cleaned by acetone and ethanol prior to tests. The potentiodynamic polarization (PDP) test and electrochemical impendence spectroscopy (EIS) test were

$\overline{{ }^{*} \text { Corresponding author: fzhang@sues.edu.cn }}$ 
systematically conducted. Before the PDP and EIS test, the samples were pre-immersed in the solution for $1 \mathrm{~h}$ to reach the stable open circuit potential value. The PDP tests were performed at a scan rate of $1 \mathrm{mV} \cdot \mathrm{s}^{-1}$. The frequency range of EIS tests was from $100 \mathrm{kHz}$ to $100 \mathrm{mHz}$, and the applied amplitude of sinusoidal potential was $5 \mathrm{mV}$.

\section{Results and discussion}

Figure 1(a) reports the EIS Nyquist plots of samples hydrothermally treated at $120^{\circ} \mathrm{C}$ for different times. It can be seen that all the plots have a small segment of inductive loop in the low frequency region and a relative large capacitive arc in the high and intermediate frequency region. The appearance of inductive reactance is caused by the induction period of pitting [2]. The capacitive arc in the high and intermediate frequency region represents the resistance capacitance relaxation process composed of charge transfer resistance and double electric layer capacitance, which often reflects the corrosion resistance [3].

It is clear that the radii of capacitive arc increased with increasing the duration of hydrothermal treatment. The equivalent circuit is shown in Fig. 1(b) in which $R_{s}$ represents the solution resistance, $\mathrm{CPE}$ is the constant phase element and $R_{p}$ is the polarization resistance. The fitted $R_{p}$ values are listed in Table 1 . It is also clear that the $R_{p}$ value increased with increasing HT time. Therefore, the corrosion resistance of ZE41A magnesium alloy can be improved by prolonging the HT time.

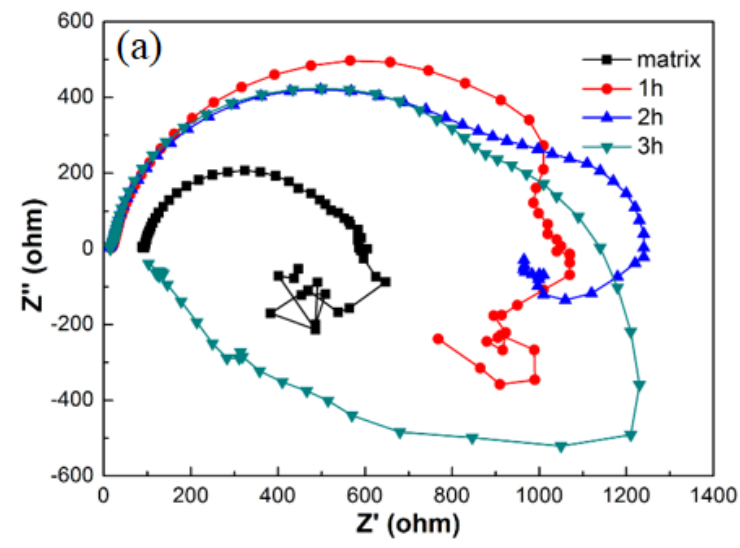

(b)

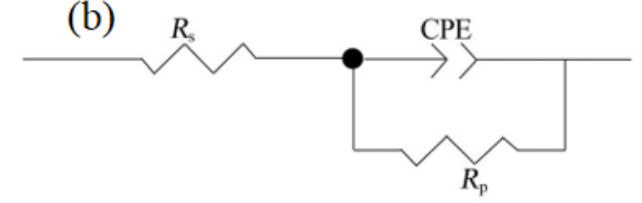

Fig. 1. (a) EIS Nyquist plots of HT treated samples at $120{ }^{\circ} \mathrm{C}$ for different times; (b) equivalent circuit.
Table 1. Fitted $R_{p}$ values of $H T$ treated samples at $120{ }^{\circ} \mathrm{C}$ for different times.

\begin{tabular}{|c|c|}
\hline Samples & $\begin{array}{c}\mathbf{R}_{\mathbf{p}} \\
(\mathbf{o h m})\end{array}$ \\
\hline Matrix & 608 \\
\hline $120-1 \mathrm{~h}$ & 956 \\
\hline $120-2 \mathrm{~h}$ & 1035 \\
\hline $120-3 \mathrm{~h}$ & 1147 \\
\hline
\end{tabular}

The EIS Nyquist plots and PDP curves of HT treated samples at different time for three hours is illustrated in Fig. 2. It is obvious that in Fig. 2 (a), the radii of capacitive arc increased with increasing the temperature of HT treatment indicating the increase of corrosion resistance. The fitted electrochemicl paramters are listed in Table 2. It is clear that with increasing the HT temperature, $\mathrm{R}_{\mathrm{p}}$ value of HT treated samples also increased. The sample treated at $160{ }^{\circ} \mathrm{C}$ for three hours shows the highest $\mathrm{R}_{\mathrm{p}}$ value. In Fig. 2 (b), it can be found the value of corrosion potential $\mathrm{E}_{\text {corr }}$ increased from $-1.616 \mathrm{~V}$ to $1.593 \mathrm{~V}$ after HT treatement at $120{ }^{\circ} \mathrm{C}$ for three hours. When the HT treatment was conducted at elevated temperatures, this value also increased to higher ones $\left(-1.443 \mathrm{~V}\right.$ for $140{ }^{\circ} \mathrm{C}$ and $-1.400 \mathrm{~V}$ for $160{ }^{\circ} \mathrm{C}$ ). Another important parameter that can be found from Fig. 2 (b) is the corrosion current density $I_{\text {corr. }}$ Generally speaking, the lower the corrosion current density is, the slower the corrosion rate will be. It is also clear that the value of Icorr decresed with increasing the HT temperatures. For the matix, its $\mathrm{I}_{\text {corr }}$ value is as high as $3.5 \times 10^{-5} \mathrm{~A} / \mathrm{cm}^{2}$. This value decreased for about one magnitude after HT treatment at $160{ }^{\circ} \mathrm{C}$. Therefore, it can be concluded that both increasing the HT time and temperature can improve the corrosion resistance of ZE41A magnesium alloy in Hank's solution. The sample treated at $160{ }^{\circ} \mathrm{C}$ for three hours shows the best corrosion resistance in Hank's solution in terms of the highest polarization resistance, highest corrosion potential and relative low corrosion current density.

Table 2 Fitted electrochemical parameters of HT treated samples at different temperature for three hours.

\begin{tabular}{|c|c|c|c|}
\hline \multirow{2}{*}{ Samples } & \multicolumn{3}{|c|}{ Parameters } \\
\cline { 2 - 4 } & $\begin{array}{c}\mathbf{R}_{\mathbf{p}} \\
(\mathbf{o h m})\end{array}$ & $\mathbf{E}_{\text {corr }} \mathbf{( V )}$ & $\begin{array}{c}\text { Icorr } \\
\left(\mathbf{A} / \mathbf{c m}^{\mathbf{2}}\right)\end{array}$ \\
\hline Matrix & 608 & -1.616 & $3.5 \times 10^{-5}$ \\
\hline $120-3 \mathrm{~h}$ & 1147 & -1.593 & $1.6 \times 10^{-5}$ \\
\hline $140-3 \mathrm{~h}$ & 1205 & -1.443 & $2.6 \times 10^{-6}$ \\
\hline $160-3 \mathrm{~h}$ & 2632 & -1.400 & $2.8 \times 10^{-6}$ \\
\hline
\end{tabular}



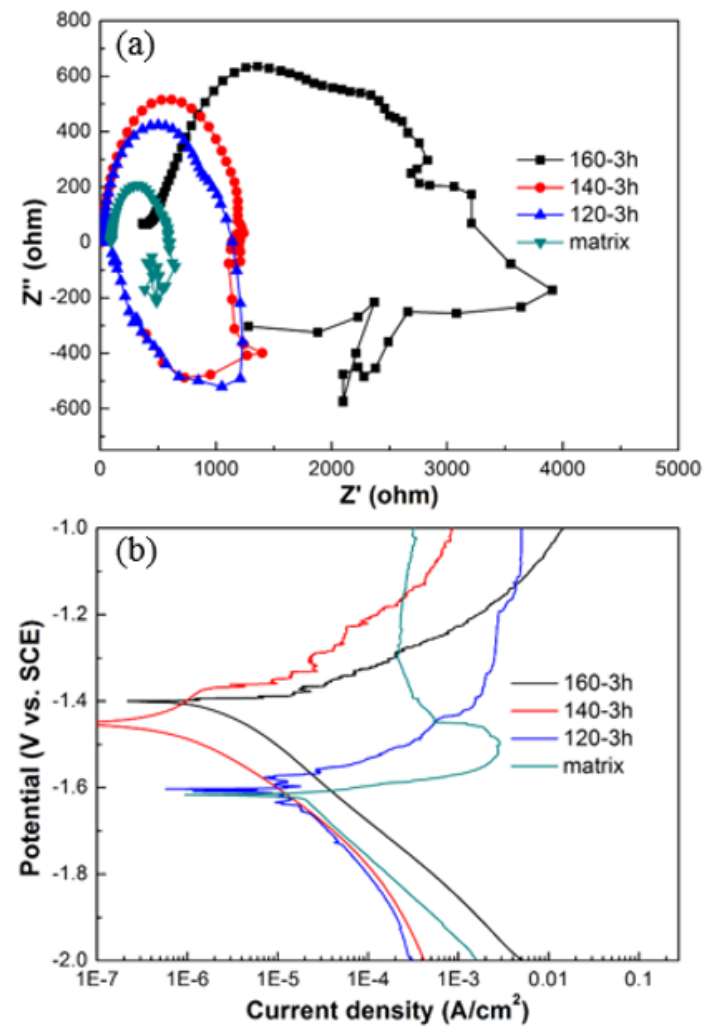

Fig. 2. (a) EIS Nyquist plots of HT treated samples at different temperatures for three hours; (b) PDP curves of HT treated samples at different temperatures for three hours.

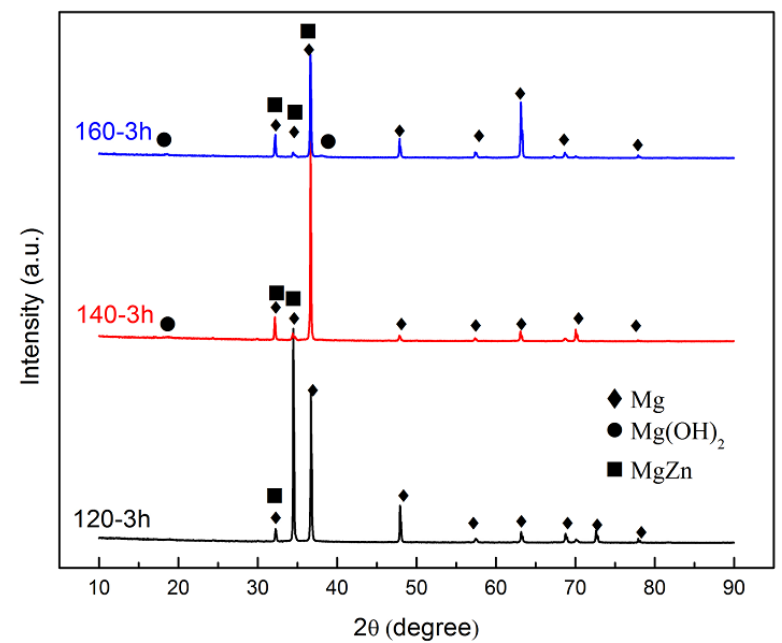

Fig. 3. XRD profiles of HT treated samples

The improvement of corrosion resistance can be attributed to morphologies changes and formation $\mathrm{MgO} / \mathrm{Mg}(\mathrm{OH})_{2}$ protective film on the surface after HT treatment. To explain the best corrosion resistance for the sample HT treated at $160{ }^{\circ} \mathrm{C}$ for 3 hours, XRD and SEM are carried out.

XRD profiles of HT treated samples at different temperatures for three hours are shown in Fig. 3. It is clear that when the HT temperature is low, no obvious $\mathrm{Mg}(\mathrm{OH})_{2}$ peaks can be found. However, when the HT temperature increased to $140{ }^{\circ} \mathrm{C}$ and $160{ }^{\circ} \mathrm{C}$, the intensity of $\mathrm{Mg}$ peaks decreases and $\mathrm{Mg}(\mathrm{OH})_{2}$ appears when HT temperature is higher than $140{ }^{\circ} \mathrm{C}$. Therefore, the increase of HT

temperature is favorable for the formation of more corrosion resistant HT coatings.

The formation of magnesium hydroxide at elevated HT temperatures can also be confirmed by SEM analysis. Fig. 4 shows the SEM morphologies of HT treated samples at 140 and 160 for three hours. The corresponding results of EDS analysis is shown in Table 3.

It can be seen from Fig. 4 that after HT treating at $140{ }^{\circ} \mathrm{C}$ for 3 hours, a coarse cauliflower-like structure can be found with some pits on the surface of ZE41 A Mg alloy. It is obvious that the amount of $\mathrm{O}$ is rather low indicating only a few magnesium hydroxide forms on its surface after HT treatment at this temperature. However, when the HT temperature is increased to $160{ }^{\circ} \mathrm{C}$, a fine needle-like surface structure forms.

The EDS analysis of HT treated samples shows that the increase of HT temperature from $140{ }^{\circ} \mathrm{C}$ and $160{ }^{\circ} \mathrm{C}$ leads to a higher amount of oxygen on the surface layer indicating the further formation of more magnesium hydroxide on the surface at elevated temperature. These results are consistent with the XRD results. It can be therefore concluded that the increase of HT temperature will change the morphologies as well as the chemical compositions of formed coatings from a relative loose structure with few magnesium hydroxides into a fine dense one with higher amount of magnesium hydroxide. Such changes of HT coating result in the best anticorrosion behavior for ZE41 A Mg alloy in Hank's solution.

Table 3. EDS results of hydrothermally treated magnesium alloys.

\begin{tabular}{|c|c|c|}
\hline \multirow{2}{*}{ Element } & \multicolumn{2}{|c|}{ Samples (Wt.\%) } \\
\cline { 2 - 3 } & $\mathbf{1 4 0 - 3 h}$ & $\mathbf{1 6 0 - 3 h}$ \\
\hline $\mathrm{Mg}$ & 96.44 & 83.54 \\
\hline $\mathrm{O}$ & 03.56 & 16.46 \\
\hline
\end{tabular}



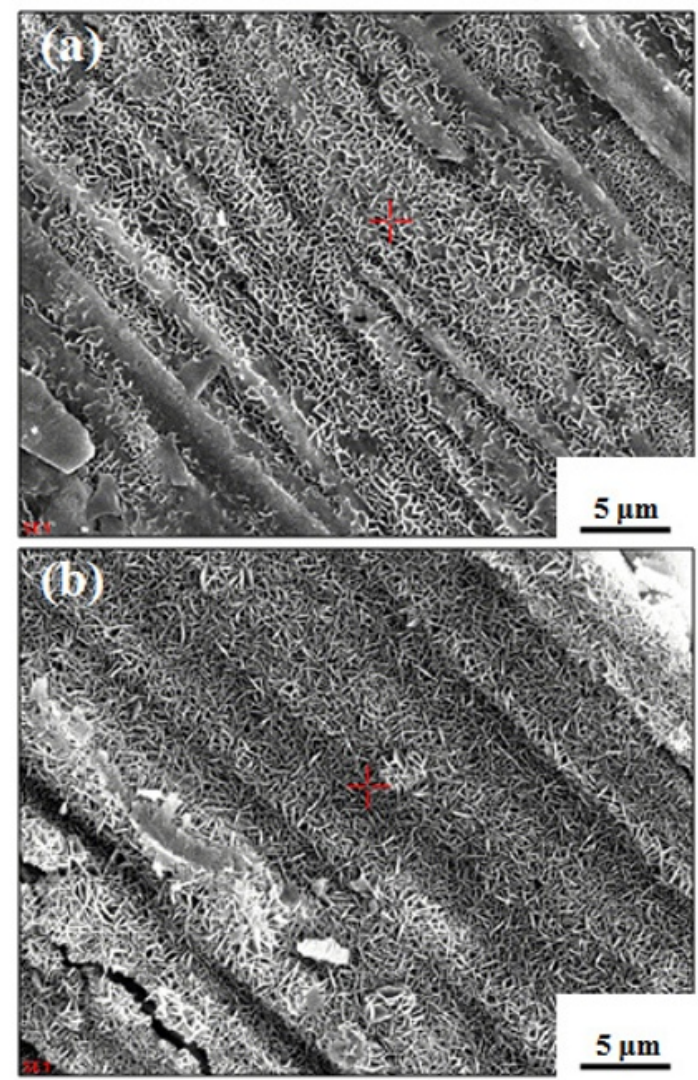

Fig. 3. SEM morphologies of HT treated samples at: (a) $140{ }^{\circ} \mathrm{C}$ for three hours and (b) $160^{\circ} \mathrm{C}$ for three hours.

\section{Conclusions}

Prolonged HT time from one hour to three hours is favourable to enhance the electrochemical corrosion properties for ZE41A Mg alloy in Hank's solution. Increasing the HT temperature changes the surface morphologies of ZE41A Mg alloy and results in more amount of magnesium hydroxide in the surface which finally improves its electrochemical corrosion properties in Hank's solution. The optimum HT condition is found as $160{ }^{\circ} \mathrm{C}$ and three hours.

\section{Acknowledgements}

FZ would like to thank Shanghai University of Engineering Science for a starting fund (0235-E3-050719-05020). This work is financially supported by Student Innovative Training Program of Shanghai (CS2005005).

\section{References}

1. A. Atrens, G. Song, Z. Shi, A. Soltan, S. Johnston, M.S. Dargusch, Understanding the Corrosion of $\mathrm{Mg}$ and $\mathrm{Mg}$ Alloys, Encyclopedia of Interfacial Chemistry: Surface Science and Electrochemistry (Elsevier, 2018) 515-534

2. M. Esmaily, J.E. Svensson, S. Fajardo, N. Birbilis, G.S. Frankel, S. Virtanen, R. Arrabal, S. Thomas, L.G. Johansson, Progr. Mater. Sci. 89 (2017) 92-193
3. A. Atrens, G. Song, F. Cao, Z. Shi, P. K. Bowen, J. Magnesium Alloys 1 (2013) 177-200

4. F. Cao, G. Songa, A. Atrens, Corros. Sci. 111 (2016) 835-845

5. G. Song, K.A.Unocic, M. Harry III, E. Cakmak, M. P. Brady, P.E.Gannon, P. Himmer,Q. Andrews, Corros. Sci. 104 (2016) 36-46

6. S. R. Paital, A. Bhattacharya, M. Moncayo, Y. H. Ho, K. Mahdak, S. Nag, R. Banerjee, N. B. Dahotre, Surf. Coat. Tech. 206 (2012) 2308-2315

7. L. Cui, P. Qin, X. Huang, Z. Yin, R. Zeng, S. Li, E. Han, Z. Wang, Surf. Coat. Tech. 324 (2017) 560-568

8. D. Song, C. Li, N. Liang, F. Yang, J. Jiang, J. Sun, G. Wu, A. Ma, X. Ma, Mater. Design 166 (2019) 107621

9. D. Song, L. Cheng, L. Zhang, X. Ma, G. Guo, F. Zhang, J. Jiang, A. Ma, Materials 10 (2017) 858

10. R.I.M. Asri, W.S.W. Harunb, M. Samykano, N.A.C. Lah, S.A.C. Ghani, F. Tarlochan, M.R. Raza, Mater. Sci. Eng. C 77 (2017) 1261-1274

11. F. Zhang, A. Ma, J. Jiang, H. Xu, D. Song, F. Lu, Y. Nishida, Progr. Natur. Sci. Mater. Inter. 23 (2013) 420-424

12. F. Zhang, A. Ma, D. Song, J. Jiang, F. Lu, L. Zhang, D. Yang, J. Chen, Journal of Rare Earths 33 (2015) 93-101 